\title{
Analysis of Neck Trauma Patients Using the Korean National Emergency Department Information System
}

\author{
Jung Hun Kim, M.D.*, Sung Won Jung, M.D., Ph.D.*, Jin Suk Lee, M.D.*, \\ Jong-Min Park, M.D. ${ }^{*}$, Han Deok Yoon ${ }^{\dagger}$, Jung Tak Rhee ${ }^{\dagger}$, Sun Worl Kim ${ }^{\dagger}$, \\ Borami $\operatorname{Lim}^{\dagger}$, So Ra Kim ${ }^{\dagger}$, Il-Young Jung, M.D. ${ }^{\dagger}$
}

${ }^{*}$ Department of Surgery and ${ }^{\dagger}$ National Trauma System Management Office, National Medical Center,

${ }^{\ddagger}$ Department of Surgery, Asan Medical Center, University of Ulsan College of Medicine, Seoul, Korea

Correspondence to:

Sung Won Jung, M.D., Ph.D.

Department of Surgery, National

Medical Center, 245 Eulji-ro,

Jung-gu, Seoul 04564, Korea

Tel: $+82-2-2260-7462$

Fax: +82-2-2260-7466

E-mail: sungwon94@naver.com

ORCID:

http://orcid.org/0000-0002-7537-4731
Purpose: Trauma is a leading cause of death, even in previously healthy and disease-free individuals, and the mortality rate is very high in neck trauma patients. On the other hand, there have been few studies related to neck injuries. This study examined the characteristics and treatment results of trauma-related neck injuries using the data from Korean National Emergency Department Information System.

Methods: Neck trauma patients were classified using the 6th Korean Standard Disease Classification system. The patients' demographic factors, number of surgeries, and clinical results were investigated. Statistical analysis was conducted using SPSS to evaluate the annual differences in the demographic factors; mortality according to the site of injury and type of surgery; and mechanisms of injury.

Results: From 2011 to 2014, 2,458 neck trauma patients were treated in hospitals in South Korea. The number of patients admitted to regional and local emergency medical centers was $883(35.9 \%)$ and 1,502 (61.1\%), respectively. No significant annual differences were observed in age, sex ratio, location of treatment center, mortality, and injury site (vascular, tracheal, or esophageal). In addition, no significant differences in the cause of injury, performed surgery $(\%)$, and mortality according to the injured organ were observed.

Conclusion: This study revealed no annual changes in neck injury patients or differences in mortality according to injured organs. This study can be used as a basis for national research on organ-specific injuries, and may help predict the demand for future support projects for the establishment of regional trauma centers. (J Acute Care Surg 2018;8:7-12)

Key Words: Wounds and injuries, Neck

Received February 10, 2017, Revised November 23, 2017, Accepted December 1, 2017

Copyright $(2018$ by Korean Society of Acute Care Surgery

(c) This is an Open Access article distributed under the terms of the Creative Commons Attribution Non-Commercial License (http://creativecommons.org/licenses/by-nc/4.0) which permits unrestricted non-commercial use, distribution, and reproduction in any medium, provided the original work is properly cited.

ISSN 2288-5862(Print), ISSN 2288-9582(Online)

https://doi.org/10.17479/jacs.2018.8.1.7

\section{Introduction}

Trauma is a leading cause of death, even in previously healthy and disease-free individuals [1]. According to Korean National Statistical Office statistics, among the causes of death in Korea in 2016, trauma-related mortality comprised $55.2 \%$ and accounted for a very high proportion of deaths $(25.6 \%$ of suicides, $10.1 \%$ of transportation accidents, $5.1 \%$ of falling accidents, and $14.4 \%$ of other trauma-related deaths). However, there were no specialized treatment facilities for severe trauma patients, and few Korean physicians were specialized for severe trauma patients until 2011. The preventable death rate (trauma-related) was 35.2\% 
in 2010, which was high when compared to the rate in first-world countries $(20 \%)$ [2]. In this regard, the Korean Department of Health and Welfare designated 17 regional trauma-specialized centers and established 2 trauma-specialization education centers in 2013 [3]. It has now been more than 5 years since the more specialized professional treatment of trauma patients began.

The neck is protected by the spine posteriorly, the head superiorly, and the chest inferiorly, therefore, the anterior and lateral regions are most exposed to injury. The spinal cord lies posteriorly, cushioned among the vertebral bodies, muscles, and ligaments. However, the larynx and trachea are situated anteriorly and are readily exposed to harm and the esophagus and the major blood vessels lie between the airway and the spine. Therefore, the death rate is very high in trauma-related neck injury. However, there have not been many outcome studies published on the statistical results of trauma patients. In particular, there are very few results regarding trauma to each relevant organ specifically $[4,5]$.

The purpose of this study was to investigate the characteristics and treatment results of trauma-related neck injury using the Korean National Emergency Department Information System (NEDIS).

\section{Methods}

This research was based on data gathered from trauma centers in each region nationwide from 2011 to 2014 from the NEDIS of the National Medical Center. We investigated and analyzed emergency room (ER) patients treated for domestic trauma with a focus on neck trauma. This research was approved by the Institutional Review Board of National Medical Center (IRB no. H-1802-087-006).

The emergency care system refers to relocation of manpower, equipment, and facilities, so that they can provide prompt and effective medical care in the event of an emergency in a certain area. This system provides safe and rapid patient transfers to a hospital suitable for treatment, and the hospital supports emergency medical staff to focus on medical treatment. The Ministry of Health and Welfare evaluates the ER of each hospital according to specific criteria, designates an emergency medical institution, and grades the emergency care system, with considera- tion to the local population and in balance with the needs in neighboring areas. Currently, there is one central emergency medical center, 16 regional emergency medical centers, 98 local emergency medical centers and 352 local emergency medical institutions in Korea. The central emergency medical center is currently designated and operated by the Ministry of Health and Welfare as a National Medical Center to provide effective emergency medical services and promote related policies. Regional emergency medical centers are in charge of treatment for severe emergency patients, emergency medical assistance in the event of a major disaster, and acceptance of severe emergency medical patients being transferred from other medical institutions in a specific area. These are superior general hospitals or hospitals with more than 300 beds, which is a level equivalent to Level 1 in United States (US) trauma centers. Local emergency medical centers are smaller than regional emergency medical centers. These are general hospitals in the area or hospitals with a 100 to 300 bed capacity, which correspond to Levels 2 to 3 in US trauma centers. Local emergency medical institutions are private hospitals with fewer than 100 beds, which correspond to Levels 4 to 5 in US trauma centers. Patient data were extracted from these regional emergency medical centers, local emergency medical centers, local emergency medical institutions, and the Korean Standard Classification of Diseases (KCD) 6 block, and the KCD was used as a basis for the classification of traumatic patients. The selection criteria comprised patients without diseases, patients classified as in-patients, or dead or not to be discharged from the hospital as well as those in the ER at the same time who were classified with KCD 6 block S and T codes as they were being discharged from the ER. Exclusions comprised those who had taken unidentified substances, those with addictions, and those presenting with unidentified side-effects and complications. Patients who were completely discharged from the ER were also excluded. Data were extracted based on age, sex, region, institution category, result of emergency diagnosis, and hospitalization result. In those with neck injury, re-classification was determined more precisely as tracheal, esophageal, and blood vessel or vascular injuries. If multiple injuries were present in one patient, each injury was counted and assigned to a group (Fig. 1).

Neck surgeries and radiological interventions were identified 
with the use of electronic data interchange codes (O1300, O1321, Q2341, OA633, OA638, OA639, OB633, OB638, OB639, O2073, HA601-HA606). Surgeries related to neck trauma were as follows: invasive tracheostomy, tracheal repair, esophagostomy,

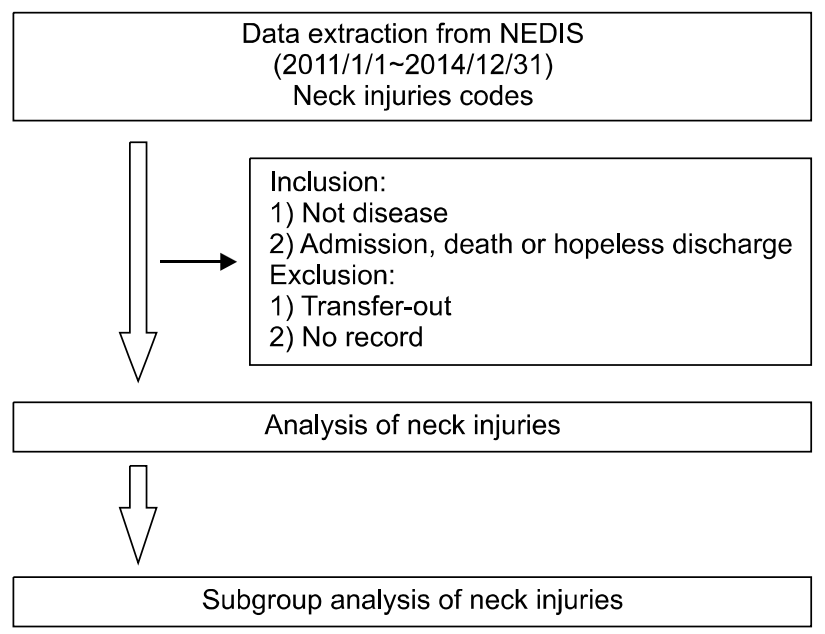

Fig. 1. The pipeline of data processing. NEDIS: National Emergency Department Information System. angioplasty, and angiography. Radiological interventions comprised angiography and arterial embolization.

Values are expressed as means $\underline{ \pm}$ standard deviation. Continuous variables in each year and for each injury mechanism were determined using a one-way ANOVA and Kruskal-Wallis test. The categorical variables were evaluated using the chi-squared test. Results were considered significant for p-value less than 0.05 .

\section{Results}

\section{Patient characteristics, treatment, and clinical outcomes according to year}

Between 2011 and 2014, 2,458 neck injury patients had been registered in NEDIS, as follows: 554 (22.5\%) in 2011, 620 (25.2\%) in 2012, $620(25.2 \%)$ in 2013, and $664(27.0 \%)$ in 2014. The average age of the neck trauma patients was $45.0 \pm 17.5$ years

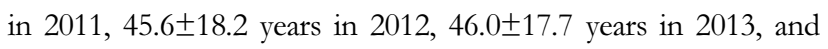
47.1 \pm 18.2 years in 2014. The annual male to female ratio was 3.74 in 2011, 3.11 in 2012, 3.53 in 2013, and 3.36 in 2014. The

Table 1. Annual comparisons in neck injury patients

\begin{tabular}{|c|c|c|c|c|c|c|}
\hline Variable & $2011 \quad(n=554)$ & $2012(\mathrm{n}=620)$ & $2013(\mathrm{n}=620)$ & $2014(\mathrm{n}=664)$ & Total $(\mathrm{n}=2,458)$ & p-value \\
\hline \multicolumn{7}{|l|}{ General characteristics } \\
\hline Age (y) & $45.0 \pm 17.5$ & $45.6 \pm 18.2$ & $46.0 \pm 17.7$ & $47.1 \pm 18.2$ & $46.0 \pm 17.9$ & 0.714 \\
\hline Male/female (ratio) & 3.74 & 3.11 & 3.53 & 3.36 & 3.43 & 0.873 \\
\hline \multicolumn{7}{|l|}{ Location of treatment centers $(\%)$} \\
\hline Regional emergency centers & $323(58.3)$ & 394 (63.6) & $376(60.7)$ & 409 (61.6) & $1,502(61.1)$ & 0.832 \\
\hline Regional emergency center zones & 207 (37.4) & $202(32.6)$ & $231(37.3)$ & $243(36.6)$ & $883(35.9)$ & 0.874 \\
\hline Regional emergency institutions & $24(4.3)$ & $24(3.9)$ & $13(2.1)$ & $12(1.8)$ & $73(3.0)$ & 0.714 \\
\hline \multicolumn{7}{|l|}{ Injury site } \\
\hline Tracheal injury & $90(16.2)$ & $103(16.6)$ & $93(15.0)$ & $109(16.4)$ & $395(16.0)$ & 0.825 \\
\hline Vascular injury & $62(11.2)$ & $64(10.3)$ & $82(13.2)$ & $95(14.3)$ & $303(12.3)$ & 0.611 \\
\hline Esophageal injury & $7(1.3)$ & $8(1.3)$ & $16(2.6)$ & $14(2.1)$ & $45(1.8)$ & 0.798 \\
\hline \multicolumn{7}{|c|}{ Surgery \& intervention for neck trauma patients } \\
\hline Surgery & $75(13.5)$ & $68(11.0)$ & $68(11.0)$ & $86(13.0)$ & $297(12.1)$ & 0.811 \\
\hline Tracheostomy & 40 & 39 & 40 & 46 & 165 & \\
\hline Tracheal repair & 15 & 12 & 14 & 17 & 58 & \\
\hline Angioplasty & 17 & 14 & 12 & 21 & 64 & \\
\hline Angiorrhapy & 1 & 0 & 0 & 1 & 2 & \\
\hline Esophagostomy & 2 & 3 & 2 & 1 & 8 & \\
\hline Intervention & $6(1.1)$ & $4(0.6)$ & $15(2.4)$ & $14(2.1)$ & $39(1.6)$ & 0.921 \\
\hline Mortality & $34(6.1)$ & $33(5.3)$ & $34(5.5)$ & $38(5.7)$ & $139(5.7)$ & 0.325 \\
\hline Expired patients in emergency room & 12 & 16 & 17 & 20 & 65 & \\
\hline Death on arrival & 4 & 7 & 6 & 8 & 25 & \\
\hline
\end{tabular}

Values are presented as mean \pm standard deviation, number only, or number (\%). 
data indicated more frequent neck trauma in males in Korea (Table 1).

Examining the data in regard to the location of treatment centers revealed a concentration of patients in regional medical institutions. In 2014, for example, among 664 patients, 409 $(61.6 \%)$ were treated in regional emergency centers, $243(36.6 \%)$ in regional emergency center zones, and $12(1.8 \%)$ in smaller regional emergency institutions (Table 1).

Among neck injury patients, surgery was required for 75 $(13.5 \%)$ patients in 2011, $68(11.0 \%)$ in 2012, $68(11.0 \%)$ in 2013, and $86(13.0 \%)$ in 2014. Additional interventional radiology procedures were performed on $6(1.1 \%)$ patients in 2011, $4(0.6 \%)$ in 2012, $15(2.4 \%)$ in 2013, and $14(2.1 \%)$ in 2014 (Table 1). Surgical procedures relating to neck trauma comprised invasive tracheostomy, tracheal repair, esophagostomy, angioplasty, and angiography (Table 1).

The mortality in neck injury patients is shown in Table 1 . In 2011, $34(6.1 \%)$ patients died, $33(5.3 \%)$ in 2012, $34(5.5 \%)$ in 2013, and $38(5.7 \%)$ in 2014. Of these, $12(2.2 \%)$ died in the ER in 2011, $16(2.6 \%)$ in 2012, $17(2.7 \%)$ in 2013, and 20 $(3.0 \%)$ in 2014. Four people $(0.7 \%)$ were declared dead on arrival (DOA) in 2011, $7(1.1 \%)$ in 2012, $6(1.0 \%)$ in 2013, and $8(1.2 \%)$ in 2014 (Table 1). Among the patients who died in the ER, 1 died without having received cardiopulmonary resuscitation (CPR) in 2011, 0 in 2012, 3 in 2013, and 0 in 2014. CPR was performed for 7 patients presenting with no vital signs in 2011, 9 in 2012, 8 in 2013, and 8 in 2014. No CPR was performed on patients with vital signs after admission in 2011, 2012, and 2013, however, in 2014, CPR was performed on 3 patients.

The differences from year to year for each factor of total neck injury patients were analyzed. As a result, there were no significant differences in age, sex ratio, treatment, hospitals, and mortality. In yearly changes in relation to the injured area, there was an increasing trend in blood vessel damage and esophageal injury, although this trend was not statistically significant (Table 1).

\section{Tracheal injury}

Among patients with neck injury, a tracheal injury was registered in $90(16.2 \%)$ patients in 2011, $103(16.6 \%)$ in 2012, $93(15.0 \%)$ in 2013, and $109(16.4 \%)$ in 2014 (Table 1). The most prevalent cause of tracheal injury was motor vehicle accidents (MVAs), in 145 (36.7\%) patients. Other causes of tracheal injury, in descending order, were penetration injuries, falls, and blunt injury (Table 2). Blunt injury did not include falls or MVAs. Of the patients with tracheal injury, 17 (4.3\%) died in the study period. Of these, $8(2.0 \%)$ died in the ER and 1 person was registered as DOA. Among the patients who died in the ER between 2011 and 2014, 1 patient died without having received $\mathrm{CPR}$, while $\mathrm{CPR}$ had been performed on 6

Table 2. Comparison of the difference according to the injury organ

\begin{tabular}{|c|c|c|c|c|c|}
\hline Variable & $\begin{array}{c}\text { Tracheal injury } \\
(\mathrm{n}=395)\end{array}$ & $\begin{array}{l}\text { Vascular injury } \\
\qquad(\mathrm{n}=303)\end{array}$ & $\begin{array}{l}\text { Esophageal injury } \\
\qquad(\mathrm{n}=45)\end{array}$ & $\begin{array}{l}\text { Total } \\
(\mathrm{n}=743)\end{array}$ & p-value \\
\hline \multicolumn{6}{|l|}{ Injury mechanism } \\
\hline Motor vehicle accidents & $145(36.7)$ & $73(24.1)$ & $15(33.3)$ & $233(31.4)$ & 0.872 \\
\hline Fall down & $70(17.7)$ & $28(9.2)$ & $8(17.8)$ & $106(14.3)$ & 0.902 \\
\hline Penetration & $94(23.8)$ & $150(49.5)$ & $18(40.0)$ & $262(35.3)$ & 0.102 \\
\hline Blunt injury & $57(14.4)$ & $19(6.3)$ & $2(4.4)$ & $78(10.5)$ & 0.831 \\
\hline Others & $24(6.1)$ & $27(8.9)$ & 0 & $51(6.9)$ & 0.491 \\
\hline Unknown & $5(1.3)$ & $6(2.0)$ & $2(4.4)$ & $13(1.7)$ & 0.843 \\
\hline \multicolumn{6}{|l|}{ Surgery \& intervention } \\
\hline Surgery performed & $103(26.1)$ & $131(43.2)$ & $14(31.1)$ & $248(33.4)$ & 0.675 \\
\hline Intervention performed & $4(1.0)$ & $9(3.0)$ & $1(2.2)$ & $14(1.9)$ & 0.728 \\
\hline Mortality & $17(4.3)$ & $22(7.3)$ & $2(4.4)$ & $41(5.5)$ & 0.676 \\
\hline Expired patients in emergency room & 8 & 7 & 0 & 15 & \\
\hline Death on arrival & 1 & 2 & 0 & 3 & \\
\hline
\end{tabular}

Values are presented as number (\%) or number only. 
patients who had arrived at the ER presenting with no vital signs. There were no instances in which CPR was performed after hospitalization on patients with vital signs during admission.

\section{Vascular injury}

Among patients with neck injury, $62(11.2 \%)$ sustained a vascular injury in 2011, $64(10.3 \%)$ in 2012, $82(13.2 \%)$ in 2013, and $95(14.3 \%)$ in 2014 (Table 1). Among the vascular injuries, penetration injuries were the most frequent 150 (49.5\%) followed by MVAs 73 (24.1\%), falls $28(9.2 \%)$ and blunt trauma 19 (6.3\%). Among the neck injuries due to penetration trauma, injury to the vasculature was the most common 150 (49.5\%), then esophageal injury 18 (40.0\%), and tracheal injury 94 (23.8\%), however, there was no statistically significant difference $(p=0.102)$.

Among all 303 vascular injury patients (2011 2014), 22 (7.3\%) died in this period and, of these, $7(2.3 \%)$ died in the ER and $2(0.7 \%)$ patients were registered as DOA. Among the patients who died in the ER, no one died without having previously received CPR and CPR had been performed on 4 patients with no vital signs. There was 1 instance in which CPR was performed after hospitalization, on a patient who presented with vital signs during admission (Table 2).

\section{Esophageal injury}

Among patients with neck injury, 7 (1.3\%) sustained esophageal injury in 2011, $8(1.3 \%)$ in 2012, $16(2.6 \%)$ in 2013, and 14 $(2.1 \%)$ in 2014 (Table 1). Penetrations were the most frequent cause of esophageal injury, followed by MVAs, falls and blunt trauma. Of the patients with vascular injury, 2 (4.4\%) died within this period. All patients who died were DOA at the hospital.

\section{Discussion}

The number of patients with neck trauma has increased steadily every year (554 in 2011, 620 in 2012, 620 in 2013, and 664 in 2014). Increased vehicular transportation and the increase in the occurrence of MVAs have led to an increasing number of trauma patients. Due to more varied and growing risk factors in the evolving modern environment, it is likely that trauma numbers will increase. Additionally, as leisure sports activities increase, trauma numbers are likely to rise even higher [6]. As the number of total trauma patients increases, the number of neck injury patients will increase accordingly. In addition, as the trauma emergency medical treatment system becomes more established, the number of medical institutions dealing with trauma will also increase. Therefore, it is likely that there will be an increase in the overall number of trauma patients reported to NEDIS accordingly.

Although statistically insignificant, patients were more likely to attend medical institutions such as a regional emergency medical center or the emergency medical service center zones. It appears that patients requiring an emergency operation or treatment were obliged to go to regional emergency medical centers or emergency medical service center zones, even if they had initially visited a regional emergency medical institution, due to deficient trauma treatment facilities.

Although the annual surgery rate did not show a significant difference among the neck trauma patients, the annual rate for performing radiological interventions slightly increased. This appears to be due to the development in imaging procedures [7-9]. In addition, as the national trauma system became established, equipment and human resources were provided and deployed to centers where existing intervention had not been previously available. As a result, these interventions were being undertaken more actively.

In the organ-related mortality rate, vascular injury was highest in $22(7.3 \%)$ patients, followed by esophageal injury in $2(4.4 \%)$ patients, and tracheal injury in 17 (4.3\%) patients.

The primary cause of neck trauma results from an MVA, followed with neck trauma due to falls. In the US, the most common cause of trauma is gunshot wounds (GSWs), followed with MVAs and falls [10]. However, Korea has effective firearms control with very few trauma cases due to GSWs, and the order of trauma-related causes of death was otherwise similar to that of other comparable non-US countries [11,12].

For every mechanism of injury, there was no significant difference in terms of the location of the damaged area. In regard to penetrating injuries, however, the proportion of patients with a vascular injury was relatively high compared to injuries in other organs, but not statistically significant. It appears that this may 
be attributable to the elasticity of blood vessels, which are less likely to be damaged through the other mechanisms of injury. Although statistically insignificant, the mortality rate and the operation rate, at $7.3 \%$ and $43.2 \%$, respectively, were higher for vascular damage than in damage to other organs. This suggests that vascular injury may affect vital signs more easily than other organs. Accordingly, it is also presumed that vascular injury led the physician to choose surgery more frequently than other types of injury. In blunt traumas and falls, there were a relatively small percentage of vascular injuries. It is considered that blood vessels were less damaged due to the anatomical location and the depth of the vessels, in addition to blood vessel elasticity.

This study has some limitations. First, where multiple injuries presented in one patient, there was a possibility of error because the statistics in each injury group may have overlapped. Second, since all clinical aspects of patients could not be collected, data in relation to the exact path of hospitalization or death had to be relied on for estimation.

Despite these limitations, this study could be used to provide baseline data for further study of organs affected in traumatic neck injury, in Korea. In particular, we believe that it may be helpful to identify the general characteristics of neck trauma with greater anatomical specificity.

In this study, we identified annual changes in neck injury patients and differences in mortality according to injured organs, and found no statistical significance. However, it is possible that if the identified limitations are addressed, statistically significant results may be obtained. This study may be of use as a basis for national research on organ-specific injuries, and may aid in predicting demand in future support projects to establish regional trauma centers.

\section{Conflict of Interest}

No potential conflict of interest relevant to this article was reported.

\section{References}

1. Gross CP, Anderson GF, Powe NR. The relation between funding by the National Institutes of Health and the burden of disease. N Engl J Med 1999;340:1881-7.

2. Coscia R, Meredith JW. Trauma ACoSCo resources for optimal care of the injured patient. Chicago: American College of Surgeons; 2006.

3. Lee KH. Optimal trauma care system in Korea. J Korean Med Assoc 2013;56:748-50.

4. Lagarde E. Road traffic injury is an escalating burden in Africa and deserves proportionate research efforts. PLoS Med 2007;4:e170.

5. Hofman K, Primack A, Keusch G, Hrynkow S. Addressing the growing burden of trauma and injury in low- and middle-income countries. Am J Public Health 2005;95:13-7.

6. Byun CS, Park IH, Oh JH, Bae KS, Lee KH, Lee E. Epidemiology of trauma patients and analysis of 268 mortality cases: trends of a single center in Korea. Yonsei Med J 2015;56:220-6.

7. Bell RB, Osborn T, Dierks EJ, Potter BE, Long WB. Management of penetrating neck injuries: a new paradigm for civilian trauma. J Oral Maxillofac Surg 2007;65:691-705.

8. Dondelinger RF, Trotteur G, Ghaye B, Szapiro D. Traumatic injuries: radiological hemostatic intervention at admission. Eur Radiol 2002;12:979-93.

9. Wei B, Hemmila MR, Arbabi S, Taheri PA, Wahl WL. Angioembolization reduces operative intervention for blunt splenic injury. J Trauma 2008;64:1472-7.

10. Sauaia A, Moore FA, Moore EE, Moser KS, Brennan R, Read RA, et al. Epidemiology of trauma deaths: a reassessment. J Trauma 1995;38:185-93.

11. Cothren CC, Moore EE, Hedegaard HB, Meng K. Epidemiology of urban trauma deaths: a comprehensive reassessment 10 years later. World J Surg 2007;31:1507-11.

12. Ameh EA, Chirdan LB, Nmadu PT. Blunt abdominal trauma in children: epidemiology, management, and management problems in a developing country. Pediatr Surg Int 2000;16: 505-9. 